\title{
The 1-exp Function as an Alternative Model of Non-Linear Saturable Kinetics
}

\author{
Frieder Keller and Dietmar Zellner
}

Division of Nephrology, Medical Department, University of Ulm, Ulm, Germany

Summary: Non-linear saturation kinetics can be described through a potency function, a trigonometric function, a logarithmic function, a hyperbolic function, or an exponential function. Saturable enzyme reaction kinetics can be alternatively formulated as a 1-exp function without the limitations of a steady-state assumption $(\mathrm{d}[\mathrm{C}] / \mathrm{d} t=0$, where $\mathrm{C}$ is the enzyme-substrate complex). The time-dependent substrate conversion (-d[S]/d $t=V_{\max }$ $\left.\left\{1-\exp \left(-K_{\mathrm{a}}[\mathrm{S}]\right)\right\}\right)$ depends on the maximum velocity $\left(V_{\max }\right)$, the association constant $\left(K_{\mathrm{a}}\right)$ and substrate concentration [S]. In contrast to the classical Michaelis-Menten equation, the 1-exp function has an explicit solution for the substrate concentration [S] in an integrated form.

$$
[\mathrm{S}]=\left(1 / K_{\mathrm{a}}\right) \ln \left[1-\left(1-\exp \left(K_{\mathrm{a}}[\mathrm{S}]_{0}\right)\right) \exp \left(-K_{\mathrm{a}} V_{\max } t\right)\right]
$$

A deceleration term must be introduced to describe enzyme reaction kinetics realistically. The 1-exp function with deceleration term can also be expanded to describe the three inhibition types of enzyme reaction kinetics.

\section{Background}

There is no simple theory of non-linear saturation kinetics. All the available models are either purely empirical, or they rely on assumptions and conditions in whose absence any given approach becomes very complicated. The following is an attempt to demonstrate that the 1exp function exhibits several advantages in describing saturation kinetics.

Non-linearity is a complex process whose dependence on time or any other independent and steady (not discrete) parameter is neither proportional nor linear. Different theoretical approaches can be used to describe non-linear saturation functions (Freundlich isotherm, Langmuir isotherm, Monot model, Larsen equation, Michaelis-Menten kinetics, 1-exp function). These saturation models are based on one of five different mathematical functions (potency function, trigonometric function, logarithmic function, hyperbolic function, exponential function).

\section{Is otherms}

The Freundlich isotherm was introduced to describe adsorption mathematically (1). It models bound concentration [B] as a potency function of unbound free concentration $[\mathrm{F}]$ with constants (a) and (b).

$$
[\mathrm{B}]=\mathrm{a}[\mathrm{F}]^{\mathrm{b}}
$$

But there is no theoretical model from which the Freundlich isotherm could be derived. It is purely empirical. What is missing is a saturation maximum and a zero origin (for $[F]>0)$ and $(a \neq 0)$.
The Langmuir isotherm was likewise developed to describe adsorption characteristics (2). In accordance with a hyperbolic function, free concentration $[F]$ is bound by absorber $[A]$, whereby $\left([A]+[B]=[B]_{\max }\right)$.

$$
\begin{aligned}
& {[\mathrm{F}]+[\mathrm{A}] \underset{k_{-1}}{\stackrel{k_{1}}{\rightleftarrows}}[\mathrm{B}]} \\
& {[\mathrm{B}]=\frac{[\mathrm{B}]_{\max }[\mathrm{F}]}{\left(k_{-1} / k_{1}\right)+[\mathrm{F}]}}
\end{aligned}
$$

The Scatchard model of ligand binding is an extension of the Langmuir isotherm (3). It comes about by adding several terms together. Accordingly, bound concentration $[B]$ is the sum of a number of hyperbolic functions, as a function of binding capacity $[P]$, the number of binding classes $(m)$, the number of bonds (n), affinity constant $(K)$, and free ligand $[\mathrm{F}]$.

$$
[\mathrm{B}]=\sum_{\mathrm{i}=1}^{\mathrm{m}}\left|\frac{\mathrm{n}_{\mathrm{i}}[\mathrm{P}]_{\mathrm{i}} K_{\mathrm{i}}[\mathrm{F}]_{\mathrm{i}}}{1+K_{\mathrm{i}}[\mathrm{F}]_{\mathrm{i}}}\right|
$$

As a reciprocal representation (1/[B] to $[F])$, the Scatchard graph serves above all to identify the number (n) of bonds.

As an alternative to Scatchard's hyperbolic model, Monot proposed a trigonometric function (4), in which bound ligand $[\mathrm{B}]$ is a function of currently unbound ligland $[F]$ and two constants $\left(a_{1}\right)$ and $\left(a_{2}\right)$.

$$
[B]=a_{1} \arctan \left(a_{2}[F]\right)
$$

This involves defining the zero origin for $([F]=0)$ and the saturation maximum $\left([B]_{\max }=a_{1} \pi / 2=a_{1} \cdot 1.5708\right)$ 
for $([F]=\infty)$. The trigonometric model is, however, purely empirical. It cannot be derived theoretically.

Larsen proposed a logarithmic function to describe binding isotherms $(5)$, where $\left(b_{2}[F]+1>0\right)$ and $\left(b_{1} \neq 0\right)$.

$$
[B]=b_{1} \ln \left(b_{2}[F]+1\right)
$$

This relation is likewise purely empirical and has no saturation maximum.

\section{Reaction kinetics}

Reaction kinetics are based on differential equations which, when solved, lead to functions of the saturation type. Solutions of reaction kinetics result - as do isotherms - in special models of non-linear saturation kinetics. The non-linear models of enzyme kinetics are more universal, although their differential equations are still non-linear in form. Reaction kinetics are, however, also helpful in understanding the aporias of the Michaelis-Menten equation.

The order of the reaction is given by the sum of the exponents of the reactands in a velocity equation.

The following holds for zero-order kinetics (6): the change in the substrate concentration remains constant over time $(-\mathrm{d}[\mathrm{S}] / \mathrm{dt}=$ const. $)$, where by definition $\left([\mathrm{S}]^{0}=1\right)$. The transformation to product $[\mathrm{P}]$ depends on the maximum velocity $\left(V_{\max }=\right.$ const.), and $(v=\mathrm{d}[\mathrm{P}] / \mathrm{d} t=-\mathrm{d}[\mathrm{S}] / \mathrm{d} t)$.

$$
\begin{aligned}
& {[\mathrm{S}] \rightarrow[\mathrm{P}]} \\
& \mathrm{d}[\mathrm{S}] / \mathrm{d} t=-V_{\max } \\
& {[\mathrm{S}]=[\mathrm{S}]_{\mathrm{o}}-V_{\max } t}
\end{aligned}
$$

Zero-order kinetics is the special case of saturated enzyme reaction kinetics with a surplus of substrate.

The following holds for first-order kinetics: the differential quotient $(-\mathrm{d}[\mathrm{S}] / \mathrm{d} t)$ is proportional to the substrate concentration [S]. The result is a linear first-order differential equation, where $\left([\mathrm{S}]^{1}=[\mathrm{S}]\right)$.

$$
\begin{aligned}
& \mathrm{d}[\mathrm{S}] / \mathrm{d} t=-k[\mathrm{~S}] \\
& {[\mathrm{S}]=[\mathrm{S}]_{\mathrm{o}} \exp (-k t)}
\end{aligned}
$$

First-order kinetics is the special case of log-linear enzyme kinetics for especially small substrate concentrations.

For second-order kinetics, the differential quotient is a function of two changing variables, $[S]^{1}$ and $[E]^{1}$, whereby $\left([\mathrm{S}]=[\mathrm{S}]_{0}\right)$ for $(t=0)$ and $\left([\mathrm{E}]_{0}-[\mathrm{E}]\right.$ $\left.=[\mathrm{S}]_{\mathrm{o}}-[\mathrm{S}]\right)$.

$$
\mathrm{d}[\mathrm{S}] / \mathrm{d} t=-k[\mathrm{~S}][\mathrm{E}]
$$

This results in a Bernoullian differential equation.

$$
\mathrm{d}[\mathrm{S}] / \mathrm{d} t=-\left([\mathrm{E}]_{0}-[\mathrm{S}]_{0}\right) k[\mathrm{~S}]-k[\mathrm{~S}]^{2}
$$

The solution, a so-called logistic function, is similar to those generally obtained as an accumulation factor in a 1-exp function.

$$
\begin{aligned}
& {[\mathrm{S}]=\frac{[\mathrm{S}]_{0}\left([\mathrm{~S}]_{0}-[\mathrm{E}]_{0}\right)}{[\mathrm{S}]_{0}-[\mathrm{E}]_{0} \exp \left(-\left([\mathrm{S}]_{0}-[\mathrm{E}]_{0}\right) k t\right)}} \\
& t=\frac{1}{k\left([\mathrm{~S}]_{0}-[\mathrm{E}]_{0}\right)} \ln \left(\frac{[\mathrm{E}]_{0}}{[\mathrm{~S}]_{0}-[\mathrm{S}]_{0}\left([\mathrm{~S}]_{0}-[\mathrm{E}]_{0}\right) /[\mathrm{S}]}\right)
\end{aligned}
$$

Second-order kinetics can be simplified for the condition ([S] $=[\mathrm{E}])$ and by using de l'Hopital's theorem (6).

$$
\begin{aligned}
& {[\mathrm{S}]+[\mathrm{S}] \rightarrow[\mathrm{P}]} \\
& \mathrm{d}[\mathrm{S}] / \mathrm{d} t=-k[\mathrm{~S}]^{2} \\
& \mathrm{k} t=1 /[\mathrm{S}]-1 /[\mathrm{S}]_{\circ} \\
& {[\mathrm{S}]=\frac{1}{1 /[\mathrm{S}]_{\mathrm{o}}+k t}}
\end{aligned}
$$

The relation of reactand [S] to time $(t)$ is hyperbolic.

\section{Enzyme reaction kinetics}

Enzyme reaction kinetics is a rule not treated as a special case of reaction kinetics, but is usually seen as its pendant, since in enzyme reaction kinetics the enzyme, as a partner in the reaction, is not consumed. Also, the bound and unbound enzyme concentrations, as in the case of isotherms, are not independent variables.

Enzyme reaction kinetics take on the character of a universal model of non-linear saturation kinetics when they are analysed in the form of differential equations. This is usually accomplished by describing the time-dependent change $(\mathrm{dx} / \mathrm{d} t)$. But saturation kinetics are also possible as a function of any other steady variable (dx/dy).

The Michaelis-Menten equation was derived in 1913 as just such a differential equation for time-dependent enzyme reaction kinetics (7). Substrate [S] and enzyme [E] form a complex [C] that is transformed into product [P].

$$
[\mathrm{S}]+[\mathrm{E}] \underset{k_{-1}}{\stackrel{k_{1}}{\rightleftarrows}}[\mathrm{C}] \stackrel{k_{2}}{\longrightarrow}[\mathrm{P}]+[\mathrm{E}]
$$

It could be taken as a basis for micro-kinetics that ([S] $\left.+[\mathrm{C}]+[\mathrm{P}]=[\mathrm{S}]_{0}\right)$ with $(\mathrm{d}[\mathrm{S}] / \mathrm{d} t+\mathrm{d}[\mathrm{C}] / \mathrm{d} t$ $+\mathrm{d}[\mathrm{P}] / \mathrm{d} t=0$ ). For the analysis of subsequent derivations, however, the condition $(\mathrm{d}[\mathrm{C}] / \mathrm{d} t=0)$ must be assumed, and this cannot be valid according to the true enzyme reaction kinetics (fig. 1). Therefore, since the complex is only hypothetical, the macro-kinetics approach assumes from the outset that $(\mathrm{d}[\mathrm{S}] / \mathrm{d} t+\mathrm{d}[\mathrm{P}] / \mathrm{d} t$ $=0)$ with the net result of the process $\left([S]+[P]=[S]_{0}\right.$ $=$ const.). Thus, the differential equation of the velocity is $(v=-\mathrm{d}[\mathrm{S}] / \mathrm{d} t=\mathrm{d}[\mathrm{P}] \mathrm{d} t)$.

It can be stated that $\left(\left|[E]_{\max }\right|=\left|[C]_{\max }\right|\right)$ since the complex is at maximum when the free enzyme is zero, and 
the free enzyme is at maximum where the complex is zero (fig. 1). This follows from the law of mass conservation $\left([E]+[C]=[E]_{\max }\right)$. But any theoretical derivation of the Michaelis-Menten equation requires one of three possible assumptions restricting its validity to these three special cases.

1) Michaelis \& Menten assumed that, as compared with the formation of the enzyme substrate complex [C], the time-dependent transformation into product $[\mathrm{P}]$ is so slow as to be negligible $\left(k_{2} \ll k_{-1}\right)$, whereby $\left(V_{\max }=\right.$ $\left.k_{2}[\mathrm{C}]_{\max }\right)$ with the boundary conditions $\left([\mathrm{S}]=[\mathrm{S}]_{\mathrm{o}}\right)$ for $(t=0)$. As a special case, the Michaelis-Menten approach contains the Langmuir isotherm $\left(k_{2}=0\right)$.

$$
\begin{aligned}
& -\mathrm{d}[\mathrm{S}] / \mathrm{d} t=k_{2}[\mathrm{C}] \\
& {[\mathrm{C}]=\left(k_{1} / k_{-1}\right)[\mathrm{C}]_{\max }[\mathrm{S}] /\left(1+[\mathrm{S}] k_{1} / k_{-1}\right)} \\
& -\mathrm{d}[\mathrm{S}] / \mathrm{d} t=k_{2}[\mathrm{C}]_{\max }[\mathrm{S}] /\left(k_{-1} / k_{1}+[\mathrm{S}]\right)
\end{aligned}
$$

This is a differential equation with separate variables. For the above conditions, the Michaelis constant is an equilibrium constant $\left(K_{\mathrm{m}}=k_{-1} / k_{1}\right)$.

$$
-\mathrm{d}[\mathrm{S}] / \mathrm{d} t=\frac{V_{\max }[\mathrm{S}]}{K_{\mathrm{m}}+[\mathrm{S}]}
$$

To integrate this hyperbolic function, the condition must be stated $([\mathrm{S}]+[\mathrm{P}]=$ const. $)$, yielding $(v=-\mathrm{d}[\mathrm{S}] / \mathrm{d} t$ $=\mathrm{d}[\mathrm{P}] / \mathrm{d} t)$. There is, however, an explicit integrated solution to the Michaelis-Menten equation only for time, not for the substrate concentration (7); here $\left([S]=[S]_{0}\right)$ for $(t=0)$.

$$
t=\frac{[\mathrm{S}]_{0}-[\mathrm{S}]}{V_{\max }}+\frac{K_{\mathrm{m}}}{V_{\max }} \ln \left(\frac{[\mathrm{S}]_{0}}{[\mathrm{~S}]}\right)
$$

A clear-cut, constant function for the substrate [S] is only implicit.

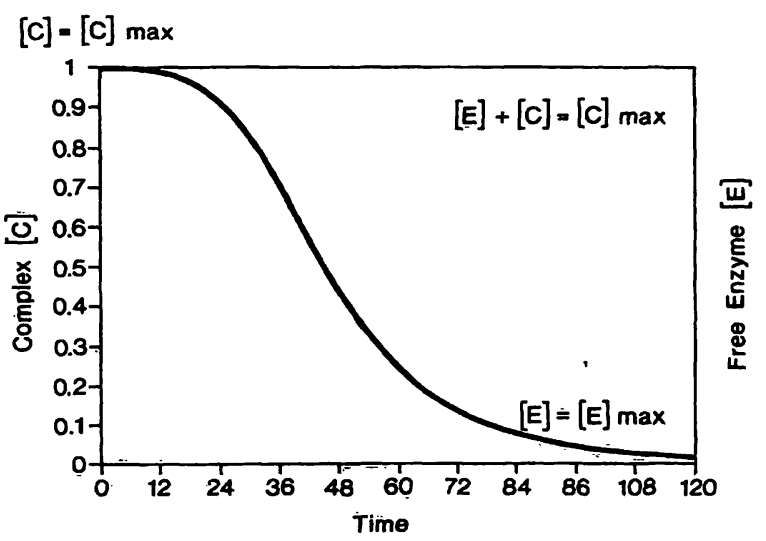

Fig. 1 Continuous enzyme kinetics. Substrate [S] and free enzyme $[E]$ form a substrate-enzyme complex $[C]$, where $([C]+[E]$ $=$ const.) and the maximum amounts are equal $\left(\left|[C]_{\max }\right|=\left|[E]_{\max }\right|\right)$. The boundary conditions are ([S] $\left.=[S]_{0}\right)$ for $(t=0)$, and $([C]$ $\left.=[\mathrm{C}]_{\max }\right)$ for $\left([\mathrm{S}]_{0} \gg K_{\mathrm{m}}\right)$. The complex is $\left([\mathrm{C}]<[\mathrm{C}]_{\max }\right)$ for $([S] \rightarrow 0)$, where $([S] \rightarrow 0)$ for $(t \rightarrow \infty)$. The complex decreases with time, becoming less than zero $(\mathrm{d}[\mathrm{C}] / \mathrm{d} t<0)$. For the nonlinear part of enzyme kinetics, therefore, the steady-state assumption $(\mathrm{d}[\mathrm{C}] / \mathrm{d} t \approx 0)$ cannot be valid.
2) Independently of Michaelis \& Menten, Van Slyke \& Cullen one year later derived the same equation $(8)$. The formation of the enzyme-substrate complex can be understood as a second-order reaction $\left(k_{-1}=0\right)$ followed by a first-order reaction (the transformation into the product) whereby $\left(V_{\max }=k_{2}[\mathrm{C}]_{\max }\right)$ and ([E] $=[\mathrm{C}]_{\max }-[\mathrm{C}]$ ).

$$
-\mathrm{d}[\mathrm{S}] / \mathrm{d} t=k_{1}[\mathrm{~S}][\mathrm{E}]
$$

The net result of the macro-kinetics is $(-\mathrm{d}[\mathrm{S}] / \mathrm{d} t$ $\left.=k_{2}[\mathrm{C}]\right)$, while the micro-kinetics demand that $(\mathrm{d}[\mathrm{C}] / \mathrm{d} t=0)$.

$$
\begin{aligned}
-\mathrm{d}[\mathrm{S}] / \mathrm{d} t & =k_{1}[\mathrm{~S}][\mathrm{C}]_{\max }-k_{1}[\mathrm{~S}](-\mathrm{d}[\mathrm{S}] / \mathrm{d} t) / k_{2} \\
-\mathrm{d}[\mathrm{S}] / \mathrm{d} t & =\frac{V_{\max }[\mathrm{S}]}{K_{\mathrm{m}}+[\mathrm{S}]}
\end{aligned}
$$

In contrast to the Michaelis constant $\left(K_{\mathrm{m}}=k_{-1} / k_{1}\right)$, Van Slyke \& Cullen define the constant $\left(K_{\mathrm{m}}=k_{2} / k_{1}\right)$.

3) Briggs \& Haldane attempted to describe enzyme reaction kinetics in even more general terms (9). They started out with the differential equation for the complex $[C]$, for which $\left([E]=[C]_{\max }-[C]\right)$ also applies.

$$
\begin{aligned}
& d[C] / d t=k_{1}[\mathrm{~S}][\mathrm{E}]-k_{-1}[\mathrm{C}]-k_{2}[\mathrm{C}] \\
& {[\mathrm{C}]=}\left(k_{1}[\mathrm{C}]_{\max }[\mathrm{S}]-d[\mathrm{C}] / d t\right) / \\
&\left(k_{-1}+k_{2}+k_{1}[\mathrm{~S}]\right)
\end{aligned}
$$

According to Wong, this results in the exact differential equation of enzyme kinetics, although there is no explicit solution for it (10). According to the law of mass conservation, the macro-kinetics must be ([S] $+[\mathrm{P}]$ $=$ const.), and it follows for the rate processes:

$$
\begin{aligned}
-d[S] / d t & =k_{1}[\mathrm{~S}][\mathrm{E}]-k_{-1}[\mathrm{C}] \\
& =d[\mathrm{P}] / d t=k_{2}[\mathrm{C}]
\end{aligned}
$$

This results in the steady state condition ([S][E]/[C] $\left.=\left(k_{-1}+k_{2}\right) / k_{1}\right)$ in contrast to the equilibrium condition ([S][E]/[C] $\left.=k_{-1} / k_{1}\right)$. The definitions $\left(V_{\max }=k_{2}\right.$ $\left.[C]_{\max }\right)$ and $\left(K_{\mathrm{m}}=\left(k_{-1}+k_{2}\right) / k_{1}\right)$ apply; and for the net result of the process, the velocity is $(v=-d[S] / d t)$.

$$
\begin{aligned}
& -d[S] / d t=k_{2}[\mathrm{C}] \\
& -d[S] / d t=\frac{V_{\max }[\mathrm{S}]-\left(k_{2} / k_{1}\right) d[C] / d t}{K_{\mathrm{m}}+[\mathrm{S}]}
\end{aligned}
$$

Briggs \& Haldane define the constant $\left(K_{\mathrm{m}}=\left(k_{-1}\right.\right.$ $\left.+k_{2}\right) / k_{1}$ ) more comprehensively than do Michaelis \& Menten $\left(K_{\mathrm{m}}=k_{-1} / k_{1}\right)$ or Van Slyke $\left(K_{\mathrm{m}}=k_{2} / k_{1}\right)$. Only when the change in concentration of the complex is very slight $(d[C] / d t \approx 0)$, or a steady-state has occurred, $(d[C] / d t=0)$, can enzyme reaction kinetics be derived according to Briggs \& Haldane, where the steady state assumption leads to the simplification $(-d[S] / d t \rightarrow$ $-\mathrm{d}[\mathrm{S}] / \mathrm{d} t)$.

$$
-\mathrm{d}[\mathrm{S}] / \mathrm{d} t=\frac{V_{\max }[\mathrm{S}]}{K_{\mathrm{m}}+[\mathrm{S}]}
$$


The problems involved in the steady-state condition $(d[C] / d t=0)$ become clear when the analysis is not restricted to the initial kinetics with different ratios of substrate concentrations to enzyme concentrations, but includes the continuous course of enzyme reaction kinetics over time in the form of a progression curve $(11,12)$.

The steady-state condition $(d[C] / d t=0)$ applies above all for high substrate concentrations, when there is a surplus of substrate ([S] $\left.\gg K_{\mathrm{m}}\right)$. A range of enzyme saturation $\left([C]=[C]_{\max }\right)$ of this kind, however, conforms to zero-order linear kinetics, and thus no function of a saturation type is required.

$$
\begin{aligned}
& -\mathrm{d}[\mathrm{S}] / \mathrm{d} t=V_{\max } \\
& {[\mathrm{S}]=[\mathrm{S}]_{\mathrm{o}}-V_{\max } t}
\end{aligned}
$$

For the range of very small substrate concentrations ([S] $\ll K_{\mathrm{m}}$ ), on the other hand, first-order log-linear kinetics applies, and the assumption of a steady-state condition $(\mathrm{d}[\mathrm{C}] / \mathrm{d} t=0)$ is unnecessary, since the relative change of the complex is negligible $\left([\mathrm{C}] \ll[C]_{\max }\right)$.

$$
\begin{aligned}
& -\mathrm{d}[\mathrm{S}] / \mathrm{d} t=\frac{V_{\max }}{K_{\mathrm{m}}}[\mathrm{S}] \\
& {[\mathrm{S}]=[\mathrm{S}]_{\mathrm{o}} \exp \left(-\frac{V_{\max }}{K_{\mathrm{m}}} t\right)}
\end{aligned}
$$

But there is no enzyme saturation for the range of nonlinear enzyme kinetics. Consequently, the complex must decrease for decreasing substrate concentrations ([C] $\left.<[C]_{\max }\right)$. It is for this reason that the steady-state condition $(d[C] / d t=0)$ cannot hold true for non-linear enzyme reaction kinetics $\left(\mathrm{S}<K_{\mathrm{m}}\right)$. As substrate concentrations decrease, the time-dependent change of the complex $(d[C] / d t)$ reaches values that are less than zero (fig. 1).

$$
d[C] / d t<0
$$

The amounts involved show that the actual conversion velocity $(v=|-d[S] / d t|)$ as determined by Wong is greater than it would be under the steady-state assumption of Briggs \& Haldane.

$$
\begin{aligned}
& -d[C] / d t>0 \\
& |-d[\mathrm{~S}] / d t|>|-\mathrm{d}[\mathrm{S}] / \mathrm{d} t| \\
& \frac{V_{\max }[\mathrm{S}]+\left(k_{2} / k_{1}\right)(-d[C] / d t)}{K_{\mathrm{m}}+[\mathrm{S}]}>\frac{V_{\max }[\mathrm{S}]}{K_{\mathrm{m}}+[\mathrm{S}]}
\end{aligned}
$$

Here, $(d[C] / d t<0)$ and $(-d[C] / d t>0)$ hold for $([\mathrm{C}]$ $<[C]_{\max }$ ); and thus the true velocity is greater than that described by the Michaelis-Menten equation. Actual enzyme kinetics $(v=|-d[S] / d t|)$ therefore display a curve more inflected and curvelinear than the shape normally described by the hyperbolic Michaelis-Menten equation $(v=|-\mathrm{d}[\mathrm{S}] / \mathrm{d} t|)$.

\section{The 1-exp function}

A 1-exp function is - under the same assumptions and for the same parameters - more inflected than the hyperbolic Michaelis-Menten equation. With the Michaelis-Menten equation, conversion velocity is $(\nu=0.5$ $V_{\max }$ ) for the condition ([S] $=K_{\mathrm{m}}$ ); , with a 1-exp function, the velocity is greater and $\left(v=0.63 V_{\max }\right)$ applies under the same condition. This suggests that the more inflected 1-exp function should be used for true enzyme reaction kinetics $(11,12)$.

Enzyme reaction kinetics can be broken down into two steps for this purpose: first, the association of the substrate [S] with the enzyme [E] to form the substrateenzyme complex [C], and second, the transformation of the complex $[\mathrm{C}]$ into the product $[\mathrm{P}]$. The association to form a complex is concentration-dependent and is controlled by the constant $\left(K_{\mathrm{a}}\right)$, while the transformation into a product, which is time-dependent, is regulated by the constant $\left(k_{t}\right)$.

$$
\begin{aligned}
& \text { [S] } \\
& + \\
& \text { [E] } \\
& \downarrow K_{\mathrm{a}} \\
& {[\mathrm{C}] \quad \underset{k_{\mathrm{t}}}{\longrightarrow}[\mathrm{P}]+[\mathrm{E}]}
\end{aligned}
$$

This rectangular scheme indicates that enzyme reaction kinetics can be considered as a two-dimensional process, in which time and concentration are primarily independent parameters. The process can be described by a partial differential equation in matrix notation and analysed in two steps (13).

$$
\left(\operatorname{Grad}[\mathrm{C}]^{\mathrm{T}}=\left[\begin{array}{l}
\partial[\mathrm{C}] / \partial[\mathrm{S}] \\
\partial[\mathrm{C}] / \partial t
\end{array}\right]=\left[\begin{array}{c}
K_{\mathrm{a}}[\mathrm{E}] \\
-k_{t}[\mathrm{C}]
\end{array}\right]\right.
$$

Such a partial differential equation must be solved by applying the chain rule. At first and for simplicity, a linear independency might be assumed between the association and the transformation processes. A special solution to the case where this assumption does not hold will later be considered by introducing the deceleration term.

1) For simplicity, the association is assumed as constant in the partial differential equation $(\partial[\mathrm{C}] / \partial[\mathrm{S}]=$ const.), and the transformation of the complex is independent of substrate concentration. Thus, the differential equation for the time-dependent conversion $(\mathrm{d}[\mathrm{P}] / \mathrm{d} t=-\partial[\mathrm{C}] / \partial t)$ into a product $[\mathrm{P}]$ is given, whereby the following conditions apply $\left([\mathrm{C}]=[\mathrm{C}]_{\max }-[\mathrm{E}]\right)$ and $\left([\mathrm{S}]+[\mathrm{P}]=[\mathrm{S}]_{0}\right.$ $=$ const.).

$$
\begin{aligned}
& \partial[\mathrm{C}] / \partial t=-k_{t}[\mathrm{C}] \\
& -\mathrm{d}[\mathrm{S}] / \mathrm{d} t=\mathrm{d}[\mathrm{P}] / \mathrm{d} t \\
& -\mathrm{d}[\mathrm{S}] / \mathrm{d} t=k_{t}\left([\mathrm{C}]_{\max }-[\mathrm{E}]\right)
\end{aligned}
$$


2) Conversely, if in the partial differential equation the transformation into the product is assumed as constant $(\partial[\mathrm{C}] / \partial t=$ const. $)$, the substrate-enzyme association is independent of time. Thus, the differential equation for the substrate-dependent association $(\partial[\mathrm{C}] / \partial[\mathrm{S}])$ to form the complex [C] is given, where the law of mass action holds ([S] $[\mathrm{E}]=K_{\mathrm{a}}[\mathrm{C}]$ ). The more substrate is present, the greater is the enzyme-substrate complex concentration [C], although a maximum value cannot be exceeded $\left([E]+[C]=[C]_{\max }=\right.$ const.). The increase of the complex is associated with a decrease of the unbound enzyme.

$$
\begin{aligned}
& \partial[\mathrm{C}] / \partial[\mathrm{S}]=K_{\mathrm{a}}[\mathrm{E}] \\
& \partial[\mathrm{C}] / \partial[\mathrm{S}]=-\mathrm{d}[\mathrm{E}] / \mathrm{d}[\mathrm{S}] \\
& -\mathrm{d}[\mathrm{E}] / \mathrm{d}[\mathrm{S}]=K_{\mathrm{a}}[\mathrm{E}]
\end{aligned}
$$

Since free enzyme increases as the complex concentration decreases, the retrograde analysis reveals that the complex has been at a maximum $\left([\mathrm{C}]=[\mathrm{C}]_{\max }\right.$ ) and the free enzyme concentration has been at minimum ([E] $\left.\ll[E]_{\max }\right)$ for high substrate concentrations $\left(K_{\mathrm{a}}[\mathrm{S}] \gg 1\right)$. For the retrograde aspect of the association process, an exponential function is obtained through integration with the boundary condition $\left([E]=[E]_{\max }\right.$ ) for $([S]=0)$.

$$
[\mathrm{E}]=[\mathrm{E}]_{\max } \exp \left(-K_{\mathrm{a}}[\mathrm{S}]\right)
$$

It holds for the net amounts that $\left(\left|E_{\max }\right|=\left|C_{\max }\right|\right)$. The exponential function for the association process ([E] $\left.=[\mathrm{E}]_{\max } \exp \left(-K_{\mathrm{a}}[\mathrm{S}]\right)\right)$ can thus be inserted into the differential equation for the transformation reaction $\left(-\mathrm{d}[\mathrm{S}] / \mathrm{d} t=k_{t}\left([\mathrm{C}]_{\max }-[\mathrm{E}]\right)\right)$. A simple differential equation of non-linear saturation kinetics in the form of a 1-exp function then results from the partial differential equation as applied to enzyme reaction kinetics.

$$
-\mathrm{d}[\mathrm{S}] / \mathrm{d} t=V_{\max }\left(1-\exp \left(-K_{\mathrm{a}}[\mathrm{S}]\right)\right)
$$

This is a differential equation with separate variables, for which $\left(V_{\max }=k_{t}[\mathrm{E}]_{\max }\right)$. Like the Michaelis-Menten equation, this differential equation has a solution for time $(t)$ in an integrated form (13). In this case ([S] $\left.=[\mathrm{S}]_{0}\right)$ for $(t=0)$.

$$
t=\frac{[\mathrm{S}]_{\mathrm{o}}-[\mathrm{S}]}{V_{\max }}+\frac{1 / K_{\mathrm{a}}}{V_{\max }} \ln \left(\frac{1-\exp \left(-K_{\mathrm{a}}[\mathrm{S}]_{\mathrm{o}}\right)}{1-\exp \left(-K_{\mathrm{a}}[\mathrm{S}]\right)}\right)
$$

It holds that $(\mathrm{a}=\ln \exp (\mathrm{a}))$. In contrast to the classical Michaelis-Menten equation, therefore, the 1-exp function does have an explicit solution for the substrate concentration $[\mathrm{S}]$ in an integrated form.

$$
\begin{aligned}
{[\mathrm{S}]=} & \left(1 / K_{\mathrm{a}}\right) \ln \left[1-\left(1-\exp \left(K_{\mathrm{a}}[\mathrm{S}]_{\mathrm{o}}\right)\right)\right. \\
& \left.\exp \left(-K_{\mathrm{a}} V_{\max } t\right)\right]
\end{aligned}
$$

Approximation $(\exp (-\mathbf{x}) \rightarrow 1-\mathbf{x})$ applies for $(|x|$ $<0.1)$, and $\left(1-\exp \left(-K_{\mathrm{a}}[\mathrm{S}]_{\mathrm{o}} /\left(1-\exp \left(-K_{\mathrm{a}}[\mathrm{S}]\right)\right)\right.\right.$ is in this way simplified to form ([S $\left.]_{0} /[S]\right)$. For cases with a small substrate concentration $\left(\left|K_{\mathrm{a}}[\mathrm{S}]_{\mathrm{o}}\right|<0.1\right)$, the integrated 1 -exp function and the integrated Michaelis-Menten equation yield the same solution for the time $(t)$.

$$
t=\frac{[\mathrm{S}]_{0}-[\mathrm{S}]}{V_{\max }}+\frac{1 / K_{\mathrm{a}}}{V_{\max }} \ln \left(\frac{[\mathrm{S}]_{\mathrm{o}}}{[\mathrm{S}]}\right)
$$

The association constant $\left(K_{\mathrm{a}}\right)$ is thus the reciprocal of a real equilibrium constant, where $\left(k_{2}=0\right)$. The result is that the association constant must correspond to the reciprocal of the original Michaelis constant $\left(1 / K_{\mathrm{a}}=K_{\mathrm{m}}\right)$. That is to say, non-linear saturation kinetics in the form of a 1-exp function contain the Michaelis-Menten equation as a special solution (14).

\section{The deceleration term $v_{\text {dec }}$}

In reality, the association of substrate and enzyme is not only concentration-dependent but time-dependent as well. The time dependence of the association cannot, however, be regarded as an acceleration of the transformation of the complex into a product; it must instead be understood as a deceleration of the process. In other words, it is necessary to introduce a deceleration term $\left(v_{\mathrm{dec}}\right)$.

$$
\begin{aligned}
& {[\mathrm{S}]+[\mathrm{E}]} \\
& v_{\text {dec }} K_{\mathrm{a}} \\
& {[C] \underset{k_{t}}{\longrightarrow}[\mathrm{P}]+[\mathrm{E}]}
\end{aligned}
$$

The deceleration may not be defined as a function of the complex [C], otherwise it would not be discernible from the transformation process $\left(-k_{t}[\mathrm{C}]\right)$. The deceleration $\left(v_{\mathrm{dec}}\right)$ must be understood as a negative velocity, and thus as a new reaction parameter that is substracted $\left(v-v_{\mathrm{dec}}\right)$ from the transformation velocity $(-\mathrm{d}[\mathrm{S}] / \mathrm{d} t$ $=v$ ). It is thus only as a subtrahend that the deceleration term can be introduced into the 1-exp function (13).

$$
-\mathrm{d}[\mathrm{S}] / \mathrm{d} t=V_{\max }\left(1-\exp \left(-K_{\mathrm{a}}[\mathrm{S}]\right)\right)-v_{\mathrm{dec}}
$$

From the origin, the 1-exp function with deceleration term is strictly convex and comes closest to actual enzyme kinetics (13). In the simplest case, the deceleration is constant ( $v_{\text {dec }}=$ const.), and an integrated solution is obtained for time $(t)$.

$$
\begin{aligned}
t= & \frac{[\mathrm{S}]_{\mathrm{o}}-[\mathrm{S}]}{V_{\max }-v_{\mathrm{dcc}}}+\frac{1 / K_{\mathrm{a}}}{V_{\max }-v_{\mathrm{dec}}} \\
& \ln \left(\frac{V_{\max }\left(1-\exp \left(-K_{\mathrm{a}}[\mathrm{S}]_{\mathrm{o}}\right)\right)-v_{\mathrm{dec}}}{V_{\max }\left(1-\exp \left(-K_{\mathrm{a}}[\mathrm{S}]\right)\right)-\nu_{\mathrm{dec}}}\right)
\end{aligned}
$$

And again, there is also an explicit solution for substrate [S] in an integrated form, where $\left(\nu_{x}=V_{\max }-\nu_{\text {dec }}\right)$.

$$
\begin{aligned}
{[\mathrm{S}]=} & \left(1 / K_{\mathrm{a}}\right) \ln \left[\left(V_{\max } / v_{\mathrm{x}}\right)-\left(\left(V_{\max } / v_{\mathrm{x}}\right)\right.\right. \\
& \left.\left.-\exp \left(K_{\mathrm{a}}\left[\mathrm{S}_{\mathrm{o}}\right]\right)\right) \exp \left(-v_{\mathrm{x}} K_{\mathrm{a}} t\right)\right]
\end{aligned}
$$


The condition $\left(-\mathrm{d}[\mathrm{S}] / \mathrm{d} t=-v_{\text {dlec }}>0\right)$ applies for $([S]=0)$, so that a state of zero transformation is attained $(-\mathrm{d}[\mathrm{S}] / \mathrm{d} t=0)$ before all the substrate has been consumed ([S]>0); thus for $(t \rightarrow \infty)$ we find that $\left(\lim [S]=[S]_{\min }\right)$.

$$
\lim [\mathrm{S}]=[\mathrm{S}]_{\min }=\left(1 / K_{\mathrm{a}}\right) \ln \left(V_{\max } / v_{\mathrm{x}}\right)
$$

If the deceleration velocity is independent of the substrate concentration [S], it is possible to specify the substrate minimum $[\mathrm{S}]_{\min }$.

\section{The three inhibition types}

The 1-exp saturation kinetics model also makes it possible to derive the three types of inhibition involved in enzyme reaction kinetics: competitive, non-competitive, and mixed inhibition (15).

1) In non-competitive enzyme inhibition, the time- and complex-dependent change of the substrate $(-\mathrm{d}[\mathrm{S}] / \mathrm{d} t$ $=\mathrm{d}[\mathrm{P}] / \mathrm{d} t=-\partial[\mathrm{C}] / \partial t)$ is counteracted by an inhibitor concentration $(\mathrm{d}[\mathrm{H}] / \mathrm{dy})$ that changes as a function of an equidistant and independent variable $(\mathrm{y})$.

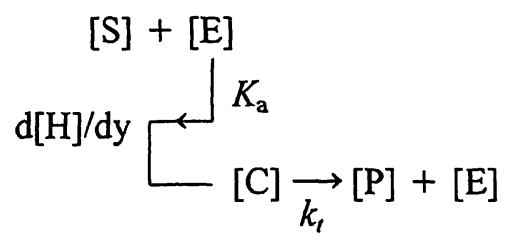

The inhibitor concentration can also be identical with the product $([\mathrm{H}]=[\mathrm{P}])$ : this is the case of non-competitive product inhibition. By intention, the meaning of the empirical variable $(y)$ is left open. Let the change of the inhibitor concentration $(\mathrm{d}[\mathrm{H}] / \mathrm{dy})$ as a function of variable (y) be proportional both to the inhibitor concentration itself and to an inhibitor constant $\left(K_{\mathrm{h}}\right)$.

$$
\begin{aligned}
& \mathrm{d}[\mathrm{H}] / \mathrm{dy}=-K_{\mathrm{h}}[\mathrm{H}] \\
& {[\mathrm{H}]=[\mathrm{H}]_{\max } \exp \left(-K_{\mathrm{h}} \mathrm{y}\right)} \\
& \mathrm{d}[\mathrm{H}] / d y=-K_{\mathrm{h}}[\mathrm{H}]_{\max } \exp \left(-K_{\mathrm{h}} \mathrm{y}\right)
\end{aligned}
$$

The deceleration term can then be defined through the inhibitor constant $\left(v_{\mathrm{dec}}=K_{\mathrm{h}}[\mathrm{H}]_{\max }\right)$ and the kinetics of non-competitive inhibition as a function of variable $(y)$, which at the outset can be selected at will.

$$
\begin{aligned}
-\mathrm{d}[\mathrm{S}] / \mathrm{d} t= & -(\mathrm{d}[\mathrm{C}] / \mathrm{d} t-\mathrm{d}[\mathrm{H}] / \mathrm{dy}) \\
-\mathrm{d}[\mathrm{S}] / \mathrm{d} t= & -v_{\mathrm{dec}} \exp \left(-K_{\mathrm{h}} \mathrm{y}\right) \\
& +V_{\max }\left(1-\exp \left(-K_{\mathrm{a}}[\mathrm{S}]\right)\right)
\end{aligned}
$$

The empirical variable (y) is introduced, in order to most generally describe the effect on the system that is exerted by changing the dynamics $(\mathrm{d}[\mathrm{H}] / \mathrm{dy})$ of the external inhibitor. If the inhibitor $[\mathrm{H}]$ depends on time $(\mathrm{y}=t)$ and/or substrate concentration $[y=[S])$ the differential equation should be calculated by the chain rule. In the simplest case $(y=0)$, the inhibition is constant $\left(v_{\text {dec }}\right.$ $=$ const.), and the kinetics of the 1-exp function with decelerator term are applicable.
2) Expansion of the model makes it possible to derive the case of competitive enzyme inhibition. It is assumed that an inhibitor complex [IC] is formed depending on an inhibitor concentration [I] and an inhibition constant $\left(K_{\mathrm{i}}\right)$.

$$
\begin{gathered}
{[\mathrm{IC}]} \\
\downarrow K_{\mathrm{i}} \\
{[\mathrm{S}]+[\mathrm{E}]+[\mathrm{I}]} \\
\stackrel{\downarrow}{\downarrow \mathrm{a}} \underset{k_{t}}{\longrightarrow}[\mathrm{P}]+[\mathrm{E}]
\end{gathered}
$$

The conditions that apply are:

$$
\begin{aligned}
& {[E]_{\max }=[E]+[C]+[I C]} \\
& \left|[E]_{\max }\right|=\left|[C]_{\max }\right|+\left|[I C]_{\max }\right|
\end{aligned}
$$

Here too, the inhibitor may be identical with the product $[\mathrm{P}]$, and thus the case involved is that of competitive product inhibition.

2.1) Proceeding from the partial differential equation $\left(\mathrm{Grad}[\mathrm{C}]=\left(K_{\mathrm{a}}[\mathrm{E}] ;-k_{t}[\mathrm{C}]\right)^{\mathrm{T}}\right)$, it is possible first to analyse the concentration-dependent association $(\partial[\mathrm{C}] /$ $\partial[S])$ for the case that the transformation of the complex is not necessarily zero, but constant $(\partial[\mathrm{C}] / \partial t=$ const.). The unbound enzyme is ambiguous with regard to association with the substrate on the one hand and inhibition through the inhibitor on the other. The boundary condition is $\left([E]=[C]_{\max }\right)$ for $([S]=0)$. Retrospectively, where $([\mathrm{S}]>0)$, it holds that for an association leading to formation of a complex [C]:

$$
\begin{aligned}
& \partial[\mathrm{C}] / \partial[\mathrm{S}]=K_{\mathrm{a}}[\mathrm{E}] \\
& -\mathrm{d}[\mathrm{E}] / \mathrm{d}[\mathrm{S}]=K_{\mathrm{a}}[\mathrm{E}] \\
& {[\mathrm{E}]=[\mathrm{C}]_{\max } \exp \left(-K_{\mathrm{a}}[\mathrm{S}]\right)}
\end{aligned}
$$

Analogously, the inhibitor [I] interacts with part of the unbound enzyme [IE] to form a complex [IC] which, in contrast to complex [C], is not transformed any further. In this case $\left([\mathrm{IC}]=[\mathrm{IC}]_{\max }-[\mathrm{IE}]\right)$, and $(|[\mathrm{IE}]|=\mid[\mathrm{IC}]$ $\max l)$ for $([\mathrm{I}]=0)$.

$$
\begin{aligned}
& \mathrm{d}[\mathrm{IC}] / \mathrm{d}[\mathrm{I}]=K_{\mathrm{i}}[\mathrm{IE}] \\
& -\mathrm{d}[\mathrm{IE}] / \mathrm{d}[\mathrm{I}]=K_{\mathrm{i}}[\mathrm{E}] \\
& {[\mathrm{IE}]=[\mathrm{IC}]_{\max } \exp \left(-K_{\mathrm{i}}[\mathrm{I}]\right)} \\
& {[\mathrm{IC}]=[\mathrm{IC}]_{\max }\left(1-\exp \left(-K_{\mathrm{i}}[\mathrm{I}]\right)\right)}
\end{aligned}
$$

We have defined $\left([\mathrm{IC}]=[\mathrm{IC}]_{\max }-[\right.$ [E] $]$ ), since no symmetry holds for the processes gouverned by $\left(K_{\mathrm{i}}\right)$ and $\left(K_{\mathrm{a}}\right)$. Thus, $\left([\mathrm{C}]=[\mathrm{E}]_{\max }-[\mathrm{E}]-[\mathrm{IC}]_{\max }+[\mathrm{IE}]\right)$, and the case is:

$$
\begin{aligned}
.[\mathrm{C}]= & {[\mathrm{E}]_{\max }-[\mathrm{E}]-[\mathrm{IC}] } \\
{[\mathrm{C}]=} & {[\mathrm{E}]_{\max }-[\mathrm{C}]_{\max } \exp \left(-K_{\mathrm{a}}[\mathrm{S}]\right) } \\
& -[\mathrm{IC}]_{\max }\left(1-\exp \left(-K_{\mathrm{i}}[\mathrm{I}]\right)\right)
\end{aligned}
$$


2.2) For the other case, i. e. that the association is constant $(\partial[\mathrm{C}] / \partial[\mathrm{S}]=$ const. $)$, it is possible to analyse the time-dependent transformation $(\delta[C] / \delta t)$ into a product $(\mathrm{d}[\mathrm{P}] / \mathrm{d} t=-\mathrm{d}[\mathrm{S}] / \mathrm{d} t)$.

$$
\begin{aligned}
-\partial[\mathrm{C}] / \partial t= & k_{t}[\mathrm{C}] \\
-\mathrm{d}[\mathrm{S}] / \mathrm{d} t= & k_{\mathrm{t}}[\mathrm{C}] \\
-\mathrm{d}[\mathrm{S}] / \mathrm{d} t= & k_{t}\left\{[\mathrm{E}]_{\max }-[\mathrm{C}]_{\max } \exp \left(-K_{\mathrm{a}}[\mathrm{S}]\right)\right. \\
& \left.-[\mathrm{IC}]_{\max }\left(1-\exp \left(-K_{\mathrm{i}}[\mathrm{I}]\right)\right)\right\}
\end{aligned}
$$

These two partial steps complete the equation for competitive enzyme inhibition, where $\left(V_{\max }=k_{t}[\mathrm{E}]_{\max }\right)$, $\left(V_{\max }-v_{\text {inh }}=k_{t}[\mathrm{C}]_{\max }\right)$, and $\left(v_{\mathrm{inh}}=k_{t}[\mathrm{IC}]_{\max }\right)$ hold true.

$$
\begin{aligned}
-\mathrm{d}[\mathrm{S}] / \mathrm{d} t= & V_{\max }-\left(V_{\max }-\nu_{\mathrm{inh}}\right) \exp \left(-K_{\mathrm{a}}[\mathrm{S}]\right) \\
& -v_{\mathrm{inh}}\left(1-\exp \left(-K_{\mathrm{i}}[1]\right)\right)
\end{aligned}
$$

There exists as yet no integrated solution to this equation.

3) The case of mixed inhibition (competitive and noncompetitive) can also be derived for the 1-exp function. To do this, it is necessary to distinguish deceleration velocity $\left(v_{\text {dec }}\right)$ from inhibition velocity $\left(v_{\text {inh }}\right)$. In viewing a mixed competitive and non-competitive inhibition, it

\section{References}

1. Freundlich H. Kapillarchiemie. Eine Darstellung der Chemie der Kolloide und verwandter Gebiete. Leipzig: Akademische Verlagsgesellschaft, 1909:94.

2. Langmuir I. The constitution and fundamental properties of solids and liquids. Part I. Solids. J Am Chem Soc 1916; $38: 2221-95$.

3. Scatchard G. The attraction of proteins for small molecules and ions. Ann NY Acad Sci 1949; 51:660-72.

4. Monot C, Netter P, Stalars MC, Martin J, Royer RJ, Gaucher A. Difficulties in applying the Scatchard model of ligand binding to proteins - proposal of new mathematical tools - application to salicylates. J Pharm Sci 1983; 72:35-41.

5. Larsen DG, Larsen FG, Brodersen R. A two-constant equation for multiple albumin-binding isotherms. J Pharm Sci 1986; 75:669-71.

6. Adam J. Einführung in die Biostatistik, Reaktionskinetik und EDV. Berlin: VEB Verlag Volk und Gesundheit, 1972:12740.

7. Michaelis L, Menten ML. Die Kinetik der Invertinwirkung. Biochem Z 1913; 49:333-69.

8. Van Slyke DD, Cullen GE. The mode of action of urease and of enzymes in general. J Biol Chem 1914; 19:141-80.

9. Briggs GE, Haldane JBS. A note on the kinetics of enzyme action. Biochem J 1925; 19:338-9. no longer makes much sense to proceed from a differential equation. No integration is possible for the mixed enzyme inhibition equation. But it is possible to combine the two equations for competitive and noncompetitive inhibition $(v=-\mathrm{d}[\mathrm{S}] / \mathrm{d} t)$.

$$
\begin{aligned}
v= & V_{\max }-v_{\text {dec }} \exp \left(-K_{\mathrm{h}} \mathrm{y}\right) \\
& -\left(V_{\max }-v_{\text {inh }}\right) \exp \left(-K_{\mathrm{a}}[\mathrm{S}]\right) \\
& -v_{\text {inh }}\left(1-\exp \left(-K_{\mathrm{i}}[\mathrm{I}]\right)\right)
\end{aligned}
$$

A numeric solution of this velocity equation might be sought by making use of a computer-aided iteration method.

The 1-exp function of saturation kinetics - especially in the integrated form - has fewer limitations than the classical Michaelis-Menten equation. Thus, it ought to be used more often, as it might enable a more accurate calculation of saturation kinetics in general $(12,14)$.

\section{Acknowledgements}

We want to thank two of the Journal's experts, Dr. med. Detlef Mix and Prof. Dr. med. Christian Trendelenburg, Frankfurt/Main, reviewing this manuscript, who agree with the abandonment of reviewer's anonymity showing us how to find the solution for the substrate concentration [S] in the integrated 1-exp function.

10. Wong JTF. Kinetics of enzyme mechanisms. London: Academic Press, 1975:2-14.

11. Keller F, Koeppe P, Emde C. Exponential function of chymotrypsin action. Enzyme 1984; 31:39-44.

12. Keller F, Giehl M, Erdmann K. The 1-exp function in nephropharmacology. Europ J Clin Pharmacol 1993; 44 Suppl 1:S27-S30.

13. Keller F, Giehl M. Saturation-type exponential function with a deceleration term for calculating nonlinear kinetics. Naturwissenschaften 1990; 77:435-6.

14. Keller F, Emde C, Schwarz A. Exponential function for calculating saturable enzyme kinetics. Clin Chem 1988; 34:2486-9.

15. Nomenclature Committee of the International Union of Biochemistry (NC-IUB). Symbolism and terminology in enzyme kinetics. Eur J Biochem 1982; 128:281 -91.

Received April 6/August 29/November 9, 1995

Corresponding author: Dr. Frieder Keller, University Ulm, Medical Department, Division of Nephrology, Robert-KochStraße 8, D-89070 Ulm, Germany 
